Research note

\title{
National and institutional productivity and collaboration in Antarctic science: an analysis of 25 years of journal publications (1980-2004)
}

\author{
Prabir G. Dastidar \\ Ministry of Earth Sciences, Block No. 9 \& 12, CGO Complex, Lodi Road, New Delhi 110003, India
}

\author{
Keywords \\ Antarctic science; journal articles; knowledge \\ mapping; network analysis; Science Citation \\ Index; scientometrics.

\section{Correspondence} \\ Prabir G. Dastidar, Ministry of Earth Sciences, \\ Block No. 9 \& 12, CGO Complex, Lodi Road, \\ New Delhi 110003, India. \\ E-mail: prabirgd11@rediffmail.com
}

doi:10.1111/j.1751-8369.2007.00017.x

\begin{abstract}
Journal publications on Antarctic science were analysed for a period of 25 years (1980-2004) through a set of scientometrics and network analysis techniques. The study is based on 10942 records (research articles, review articles, letters, etc.) with the word fragment "antarc ${ }^{\star}$ " in the title published in 961 international, peer-reviewed journals and retrieved from Thomson Scientific's Science Citation Index database. During the period under investigation, productivity increased threefold and there was a 13-fold increase in journal publications co-written by authors from different countries. The five nations with the highest output were the USA (with $26.7 \%$ of the total output), the UK $(13.8 \%)$, Australia $(9.7 \%)$, Germany $(8.8 \%)$ and Italy $(6.0 \%)$. The top five institutions in terms of journal publications were the British Antarctic Survey (972 publications), the Alfred Wegener Institute of Polar and Marine Research, Germany (475), the Australian Antarctic Division (312), the University of Tasmania, Australia (305), and the National Aeronautics and Space Administration, USA (293).
\end{abstract}

Antarctica is the fifth largest continent. This coldest, windiest and highest continent is covered with an ice sheet more than 2-km thick, on average. Having remained comparatively undisturbed and unpolluted for millions of years, the Antarctic environment is a treasure trove of information about the Earth's past. The Indian, Atlantic and Pacific oceans meet around Antarctica, and the mixing process of cold and warm waters contribute to a special regime with unique physical, chemical and biological characteristics. These waters constitute one of the world's richest biological provinces. For all these reasons, Antarctica provides unique opportunities for scientific research in diverse fields. The Antarctic Treaty Systemone of the world's most successful international agreements-ensures that Antarctica remains a natural reserve for science. There are 26 countries with seasonal or yearround stations in Antarctica (Table 1).

This paper analyses a data set of journal publications for the period 1980-2004. An attempt has been made to identify the major players in Antarctic science by identifying the nations and institutions that produced the greatest number of journal publications about Antarctica. As conducting scientific research is central to the Antarctic Treaty System, an analysis of scientific outputmeasured here in terms of journal publications - in part reflects the functioning of this set of international agreements. Similar analyses have been previously undertaken for journal publications in ocean science and technology (Dastidar 2004; Dastidar \& Ramachandran 2005), along with an earlier effort for Antarctic science (Dastidar $\delta$ Persson 2005).

\section{Materials and methods}

The data for this study were drawn from Thomson Scientific's Science Citation Index, a database available on a series of annual CD-ROMs. The Science Citation Index covers about 3700 of the world's interntional, peerreviewed scientific and technical journals, and includes publication details for research articles, review articles, news items, book reviews, letters, communications, editorial material and so forth (see http://scientific.thomson. 
Table 1 Number of stations in Antarctica and manpower deployment contributed by the 28 consultative parties to the Antarctic Treaty System (www.comnap.aq/facilities).

\begin{tabular}{|c|c|c|}
\hline Country & $\begin{array}{l}\text { No. of stations (year when } \\
\text { first station was established) }\end{array}$ & $\begin{array}{l}\text { Manpower } \\
\text { (annual peak) }\end{array}$ \\
\hline Argentina & $6(1904)$ & 417 \\
\hline Australia & 3 (1954) & 213 \\
\hline Belgium & - & - \\
\hline Brazil & 1 (1984) & 40 \\
\hline Bulgaria & $1(1988)$ & 15 \\
\hline Chile & $5(1948)$ & 224 \\
\hline Ecuador & $2(1990)$ & 88 \\
\hline Finland & $1(1989)$ & 20 \\
\hline France & 4 (1956) (one jointly with Italy) & 145 \\
\hline Germany & $2(1981)$ & 78 \\
\hline India & $1(1989)$ & 65 \\
\hline Italy & 5 (1986) (one jointly with France) & 135 \\
\hline Japan & $2(1957)$ & 150 \\
\hline the Netherlands & 0 & - \\
\hline New Zealand & $1(1957)$ & 85 \\
\hline Norway & $2(1985)$ & 44 \\
\hline China & $2(1985)$ & 70 \\
\hline Peru & 1 (1989) & 28 \\
\hline Poland & 1 (1977) & 40 \\
\hline Russia & 7 (1956) & 429 \\
\hline South Africa & 1 (1962) & 80 \\
\hline South Korea & 1 (1988) & 60 \\
\hline Spain & 2 (1989) & 28 \\
\hline Sweden & 1 (1989) & 20 \\
\hline UK & 5 (1947) & 205 \\
\hline Ukraine & 1 (1996) & 24 \\
\hline Uruguay & 1 (1984) & 60 \\
\hline USA & 3 (1955) & 1250 \\
\hline
\end{tabular}

-, Data not available.

com/products/sci/ and http://thomsonscientific.com/ free/essays/selectionofmaterial/journalselection/). The database on the CD-ROM for each year from 1980 to 2004 was searched for publications with "antarc*" in the title. This yielded 10942 records, which formed the basis of the present analysis.

To assess publication output for individual countries, each publication was given a value of 1 . In the case of a multinational publication-a publication co-written by authors with addresses in two or more different countries-each contributing country was given a fraction value where the sum of fractions equalled 1. For example, in the case of a publication written by one author with a US address and one with an address in the UK, the USA and the UK would each receive a value of 0.5 . These fractional values were summed to asssess the productivity of individual countries. It should be emphasized that this method of calculation makes no attempt to assess the actual relative contributions of the co-authors (neither, by extension, the nations they represent) by, for example, weighted scores. Rather, each co-author of an article was assigned an equal fraction. It is a widespread practice to place the co-author who has contributed disproportionately to the the work of preparing a scientific article first on the author byline (Yank \& Rennie 1999). However, other conventions may be applied and these vary across the international scientific community. Among teams of scientists who frequently publish together, the co-authors may take turns being named as lead authors $\left(\mathrm{O}^{\prime} \mathrm{Connor} \delta\right.$ Woodford 1978). In some scientific circles it may be customary to name heads of departments, laboratories or research groups as first authors $\left(\mathrm{O}^{\prime}\right.$ Connor $\&$ Woodford 1978). Some journals have clear policies about how to determine the order of authors; most do not and there is apparently no clear consensus about the meaning of the order of authors among journal editors (Yank \& Rennie 1999).

For the purposes of the analysis, publications authored by writers in the Federal Republic of Germany and the German Democratic Republic were merged under "Germany", whereas publications from writers with addresses in the USSR and Russia were combined under "Russia".

The country and names of institutions associated with the publications were isolated separately and rank ordered (Persson 2004). The most productive units were chosen to form co-occurrence matrices to which a multidimensional scaling algorithm (a SYSTAT subroutine) was applied to produce the network maps. The relative size of the circles in these diagrams indicates the relative productivity of each entity, and the lines between the circles indicate the presence of collaboration links, whereas the line thickness indicates the strength of the interconnections (Dastidar 2004; Dastidar \& Persson 2005; Dastidar \& Ramachandran 2005).

An important limitation of this study is that the data were limited to the journals in Thomson Scientific's Science Citation Index. Alhough non-English publications are included in the database, Thomson Scientific's selection criteria make it easier for English-language publications to be included for coverage (see http:// thomsonscientific.com/free/essays/selectionofmaterial/ journalselection/). In addition, journal publications that concerned Antarctica but which did not have "antarc*" in their titles were not included in this study.

\section{Results}

During the study period the output of journal publications with "antarc*" in the title increased threefold, rising from 165 in 1980 to 552 in 2004 (Fig. 1). Output peaked in 2002, with 729 publications.

Over 80 nations were represented among the authorship of the publications being analysed (Table 2). The output is highly skewed, with two countries-USA and 
Table 2 Country-by-country output of journal publications with "antarc*" in the title, based on the annual CD-ROMs of the Science Citation Index, 1980$2004(N+10$ 942). Each publication was given a value of 1 . In the case of a multinational article, each contributing country was given a fractional value where the sum of fractions equalled 1 . These fractional values were summed to asssess the productivity of individual countries. Consultative parties to the Antarctic Treaty System are indicated. (Ecuador, also a consultative party to the treaty, is not included in the table because of its very low journal publication output.) Data on per capita gross domestic expenditures on research and development are from the UNESCO Institute for Statistics (http://www.uis.unesco.org/ev.php?ID=5182=201\&ID2=DO_TOPIC).

\begin{tabular}{|c|c|c|c|c|c|c|c|c|c|}
\hline & Country & Output & $\begin{array}{l}\% \text { of } \\
\text { world } \\
\text { total }\end{array}$ & $\begin{array}{l}\text { Per capita gross domestic } \\
\text { expenditure on research and } \\
\text { development, in purchasing } \\
\text { power parity USD (year of } \\
\text { data in parentheses) }\end{array}$ & & Country & Output & $\begin{array}{l}\% \text { of } \\
\text { world } \\
\text { total }\end{array}$ & $\begin{array}{l}\text { Per capita gross domestic } \\
\text { expenditure on research and } \\
\text { development, in purchasing } \\
\text { power parity USD (year of } \\
\text { data in parentheses) }\end{array}$ \\
\hline 1 & $U_{S A}^{a}$ & 2886.90 & 26.7 & 954 (2002) & 42 & Pakistan & 2.5 & 0.0 & $5.2(2002)$ \\
\hline 2 & $\mathrm{UK}^{\mathrm{a}}$ & 1491.83 & 13.8 & 490.6 (2002) & 43 & Estonia & 2.25 & 0.0 & 98.9 (2002) \\
\hline 3 & Australiaa & 1051.85 & 9.7 & 404.5 (2000) & 44 & Philippines & 2 & 0.0 & \\
\hline 4 & Germany $^{a}$ & 948.87 & 8.8 & $686(2002)$ & 45 & Romania & 2 & 0.0 & 24.9 (2002) \\
\hline 5 & Italy & 653.21 & 6.0 & 288.7 (2001) & 46 & Singapore & 2 & 0.0 & $525.7(2002)$ \\
\hline 6 & France $^{a}$ & 526.08 & 4.9 & 611.2 (2002) & 47 & Antarctica & 1.83 & 0.0 & - \\
\hline 7 & $J^{\prime a p a n}{ }^{a}$ & 492.22 & 4.5 & $836.6(2002)$ & 48 & Monaco & 1.83 & 0.0 & - \\
\hline 8 & New Zealand ${ }^{\mathrm{a}}$ & 430.22 & 4.0 & 246.1 (2001) & 49 & Reunion & 1.5 & 0.0 & - \\
\hline 9 & Russia $^{a}$ & 305.86 & 2.8 & 102.2 (2002) & 50 & Ciskei & 1 & 0.0 & - \\
\hline 10 & Spain & 241.37 & 2.2 & 222.4 (2002) & 51 & Colombia & 1 & 0.0 & $10.5(2001)$ \\
\hline 11 & South Africa ${ }^{a}$ & 232.99 & 2.2 & 68.7 (2002) & 52 & Indonesia & 1 & 0.0 & - \\
\hline 12 & Argentina $^{a}$ & 188.37 & 1.7 & 44 (2002) & 53 & Ivory Coast & 1 & 0.0 & - \\
\hline 13 & the Netherlands ${ }^{a}$ & 152.82 & 1.4 & $536.6(2001)$ & 54 & Kenya & 1 & 0.0 & - \\
\hline 14 & India & 126.29 & 1.2 & $20.5(2000)$ & 55 & Papua New Guinea & 1 & 0.0 & - \\
\hline 15 & Belgium $^{\mathrm{a}}$ & 117.06 & 1.1 & 614.7 (2002) & 56 & Peru ${ }^{a}$ & 1 & 0.0 & $5.2(2002)$ \\
\hline 16 & Canada & 109.65 & 1.0 & $588.4(2002)$ & 57 & Portugal & 1 & 0.0 & $170.2(2002)$ \\
\hline 17 & Sweden ${ }^{a}$ & 107.30 & 1.0 & $1082.5(2001)$ & 58 & Saudi Arabia & 1 & 0.0 & - \\
\hline 18 & Poland ${ }^{a}$ & 107 & 1.0 & $62.7(2002)$ & 59 & Vanuatu & 1 & 0.0 & - \\
\hline 19 & China $^{a}$ & 90.74 & 0.8 & - & 60 & Zimbabwe & 1 & 0.0 & - \\
\hline 20 & Norway $^{a}$ & 88.73 & 0.8 & 612.2 (2002) & 61 & Bolivia & 0.5 & 0.0 & $6.9(2002)$ \\
\hline 21 & Chile $^{a}$ & 63.16 & 0.6 & 51.9 (2001) & 62 & Belarus & 0.5 & 0.0 & 35.1 (2002) \\
\hline 22 & Brazil $^{a}$ & 58.49 & 0.5 & $76.9(2000)$ & 63 & Comoros & 0.5 & 0.0 & - \\
\hline 23 & Switzerland & 50.78 & 0.5 & 740.4 (2000) & 64 & Costa Rica & 0.5 & 0.0 & $34.5(2000)$ \\
\hline 24 & Denmark & 45.97 & 0.4 & 777.6 (2002) & 65 & Latvia & 0.5 & 0.0 & $42.8(2002)$ \\
\hline 25 & South Korea & 44.53 & 0.4 & 492.3 (2002) & 66 & Luxembourg & 0.5 & 0.0 & $961.1(2000)$ \\
\hline 26 & Austria & 37.84 & 0.3 & 645.2 (2002) & 67 & Morocco & 0.5 & 0.0 & - \\
\hline 27 & Finland $^{\mathrm{a}}$ & 35.99 & 0.3 & $905.2(2002)$ & 68 & Namibia & 0.5 & 0.0 & - \\
\hline 28 & Czech Republic & 13.99 & 0.1 & - & 69 & New Caledonia & 0.5 & 0.0 & - \\
\hline 29 & Bulgaria & 10.5 & 0.1 & 34.9 (2002) & 70 & Niger & 0.5 & 0.0 & - \\
\hline 30 & Hungary & 9.16 & 0.1 & $135.3(2002)$ & 71 & Nigeria & 0.5 & 0.0 & - \\
\hline 31 & Greece & 9.08 & 0.1 & 115.8 (2001) & 72 & Qatar & 0.5 & 0.0 & - \\
\hline 32 & Ukraine $^{a}$ & 9 & 0.1 & $57.6(2002)$ & 73 & Slovenia & 0.5 & 0.0 & $286.2(2002)$ \\
\hline 33 & Ireland & 8.91 & 0.1 & $369.2(2001)$ & 74 & Sri Lanka & 0.5 & 0.0 & 5.1 (1996) \\
\hline 34 & Taiwan & 8.5 & 0.1 & - & 75 & Uruguay $^{a}$ & 0.5 & 0.0 & $20.6(2002)$ \\
\hline 35 & Israel & 7.91 & 0.1 & 997.2 (2002) & 76 & Venda & 0.5 & 0.0 & - \\
\hline 36 & Mexico & 6.16 & 0.1 & $38.3(2002)$ & 77 & Vietnam & 0.5 & 0.0 & - \\
\hline 37 & Turkey & 4.5 & 0.0 & $42.6(2002)$ & 78 & Yugoslavia & 0.5 & 0.0 & - \\
\hline 38 & Bermuda & 4.33 & 0.0 & 27.4 (1997) & 79 & Fiji & 0.33 & 0.0 & - \\
\hline 39 & Iceland & 3.90 & 0.0 & 925.7 (2002) & 80 & French Polynesia & 0.33 & 0.0 & - \\
\hline 40 & Jamaica & 3.33 & 0.0 & $3.0(2002)$ & 81 & French Guiana & 0.33 & 0.0 & - \\
\hline 41 & UKSSR & 3 & - & - & 82 & Venezuela & 0.2 & 0.0 & $20.7(2002)$ \\
\hline
\end{tabular}

${ }^{a}$ Consultative parties. -, Data not available.

UK-each contributing shares larger than $10 \%, 16$ countries each contributing shares between 1 and $10 \%$, and all the remaining countries contributing shares of less than $1 \%$ each. The share for the USA was $26.7 \%$, almost double that of the UK, which was the next most productive country, with $13.8 \%$. The five most productive countries (USA, UK, Australia, Germany and Italy) together contributed $65 \%$ of the total output. 

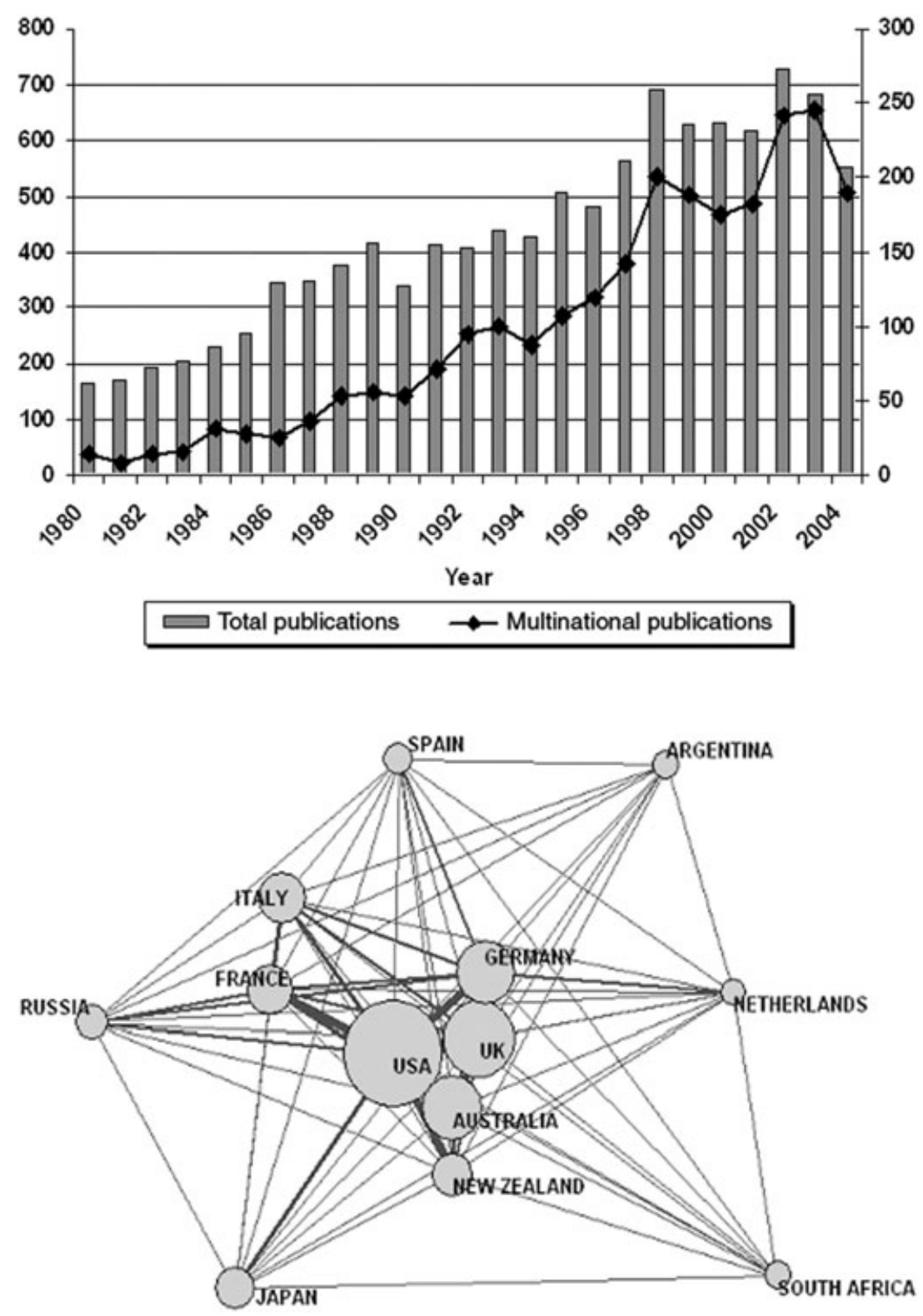

Fig. 1 Overall number of journal publications with "antarc*" in the title, and the number of these publications co-authored by writers from different countries, based on the annual CDROMs of the Science Citation Index, 1980-2004. The scale on the left-hand side of the figure indicates the overall number of publications and the scale on the right-hand side indicates the number of multinational publications.
Fig. 2 Collaboration network of the top 13 countries in terms of the output of multinational journal publications with "antarc*" in the title, based on the annual CD-ROMs of the Science Citation Index, 1980-2004 ( $N=82)$. Line thickness and proximity of the circles indicates collaboration intensity between the countries.
As shown in Fig. 1, the number and proportion of publications co-written by contributors from different countries increased over the period being examined. There were 15 multinational publications in 1980, which represented $9.09 \%$ of the total for that year. By 2004 there were 190 multinational publications, which constituted $34.42 \%$ of the total for that year. Figure 2 gives an indication of the collaborative ties between countries, with the countries with writers who most frequently coauthor publications lumped together in the middle of the diagram. American authors most frequently contribute to multinational journal publications, followed by the UK, Australia and Germany.
About 2837 organizations contributed to journal publications with "antarc*" in the title during the period studied. The 75 most productive institutions are presented in Table 3. The British Antarctic Survey topped the list, having contributed to 972 publications. In second place was the Alfred Wegener Institute for Polar and Marine Research, with 475 publications. The remaining institutions among the top five were the Australian Antarctic Division (312 publications), the University of Tasmania, Australia (305 publications), and the National Aeronautics and Space Administration, USA (294 publications). The country with the most institutions appearing in the top 75 was the USA, with 26 institutions. Australia had 
Table 3 Rank list of the 74 most productive institutes in terms of journal publications with "antarc*" in the title, based on the annual CD-ROMs of the Science Citation Index, 1980-2004.

\begin{tabular}{|c|c|c|c|c|c|}
\hline Ranking & Institution & $\begin{array}{l}\text { No. } \\
\text { articles }\end{array}$ & Ranking & Institution & $\begin{array}{l}\text { No. } \\
\text { articles }\end{array}$ \\
\hline 1 & British Antarctic Survey, UK & 972 & 39 & University of Cape Town, South Africa & 75 \\
\hline 2 & Alfred Wegener Inst. for Polar \& Marine Res., Germany & 475 & 40 & Texas A\&M University, USA & 72 \\
\hline 3 & Australian Antarctic Div., Australia & 312 & 41 & University of Cambridge, UK & 72 \\
\hline 4 & University of Tasmania, Australia & 305 & 42 & University of California, Santa Barbara, USA & 71 \\
\hline 5 & NASA, USA & 293 & 43 & University of Illinois, USA & 71 \\
\hline 6 & Ohio State University, USA & 244 & 44 & University of California, Santa Cruz, USA & 71 \\
\hline 7 & University of California, San Diego, USA & 220 & 45 & Lab Glaciol \& Geophys Environm, France & 70 \\
\hline 8 & NERC, UK & 216 & 46 & University of Texas, USA & 69 \\
\hline 9 & CNR, Italy & 214 & 47 & Arctic \& Antarctic Research Institute, Russia & 69 \\
\hline 10 & CNRS, France & 205 & 48 & Macquarie University, Australia & 68 \\
\hline 11 & National Institute of Polar Research, Japan & 196 & 49 & Woods Hole Oceanographic Institution, USA & 67 \\
\hline 12 & University of Colorado, USA & 163 & 50 & University of Paris, France & 67 \\
\hline 13 & CSIRO, Australia & 146 & 51 & Polish Academy of Sciences, Poland & 66 \\
\hline 14 & Russian Academy of Sciences, Russia & 148 & 52 & University of Siena, Italy & 65 \\
\hline 15 & NOAA, USA & 137 & 53 & University of Alaska, USA & 64 \\
\hline 16 & CALTECH, USA & 135 & 54 & University of Bremen, Germany & 62 \\
\hline 17 & University of Washington, USA & 127 & 55 & Nat Inst Water and Atmospher Res, New Zealand & 60 \\
\hline 18 & CSIC, Spain & 124 & 56 & University of Wyoming, USA & 60 \\
\hline 19 & University of Melbourne, Australia & 123 & 57 & University of Copenhagen, Denmark & 60 \\
\hline 20 & Columbia University, USA & 103 & 58 & University of Pretoria, South Africa & 60 \\
\hline 21 & University of Wisconsin, USA & 102 & 59 & Consejo Nacl Invest Cient \& Tecn, Argentina & 60 \\
\hline 22 & University of Maine, USA & 101 & 60 & University of Hawaii, USA & 59 \\
\hline 23 & University of Genoa, Italy & 100 & 61 & Chinese Academy of Sciences, China & 58 \\
\hline 24 & Antarctic CRC, Australia & 98 & 62 & Oregon State University, USA & 58 \\
\hline 25 & Argentinean Antarctic Institute, Argentina & 95 & 63 & Monash University, Australia & 56 \\
\hline 26 & University of Tokyo, Japan & 94 & 64 & University of California, USA (no specific campus & 54 \\
\hline 27 & University of Canterbury, New Zealand & 94 & & stated) & \\
\hline 28 & US Geological Survey, USA & 92 & 65 & University of Bern, Switzerland & 54 \\
\hline 29 & University of Kiel, Germany & 89 & 66 & University of California, Los Angeles, USA & 53 \\
\hline 30 & University of Alabama, USA & 88 & 67 & University of Waikato, New Zealand & 53 \\
\hline 31 & University of Otago, New Zealand & 88 & 68 & Department of Science, Australia & 52 \\
\hline 32 & University of Buenos Aires, Argentina & 85 & 69 & University of Liege, Belgium & 52 \\
\hline 33 & Australian National University, Australia & 84 & 70 & Montana State University, USA & 52 \\
\hline 34 & Christian Albrechts University of Kiel, Germany & 83 & 71 & Victoria University of Wellington, New Zealand & 52 \\
\hline 35 & DSIR, New Zealand & 82 & 72 & University of New South Wales, Australia & 49 \\
\hline 36 & Hokkaido University, Japan & 82 & 73 & National Center for Atmospheric Research, USA & 48 \\
\hline 37 & University of Auckland, New Zealand & 81 & 74 & University of Bristol, UK & 47 \\
\hline 38 & University of Utrecht, the Netherlands & 76 & & & \\
\hline
\end{tabular}

10 institutions among the top 74, New Zealand had seven, and Argentina and Germany each had four.

Data for the ten most productive organizations were used to produce the network map presented in Fig. 3. The diagram indicates frequent co-authorship between the British Antarctic Survey and the Alfred Wegener Institute for Polar and Marine Research.

\section{Discussion}

Scientific journal publications about Antarctica in the period 1980-2004 were dominated by the nations with a strong interest in the continent. Nineteen of the 20 countries producing the most publications are consultative parties to the Antarctic Treaty, and the top 20 countries included all 11 original signatories of the treaty (Table 2 ). Setting aside Canada and the 11 original signatory nations, the remaining eight countries in the top 20 gained consultative status by having conducted substantial research activity there, as provided by Article 9 of the treaty (http://www.ats.aq/).

Productivity in science is investment dependent, as is shown by the strength of the contribution to journal publications about Antarctica in 1980-2004 by the USA. 


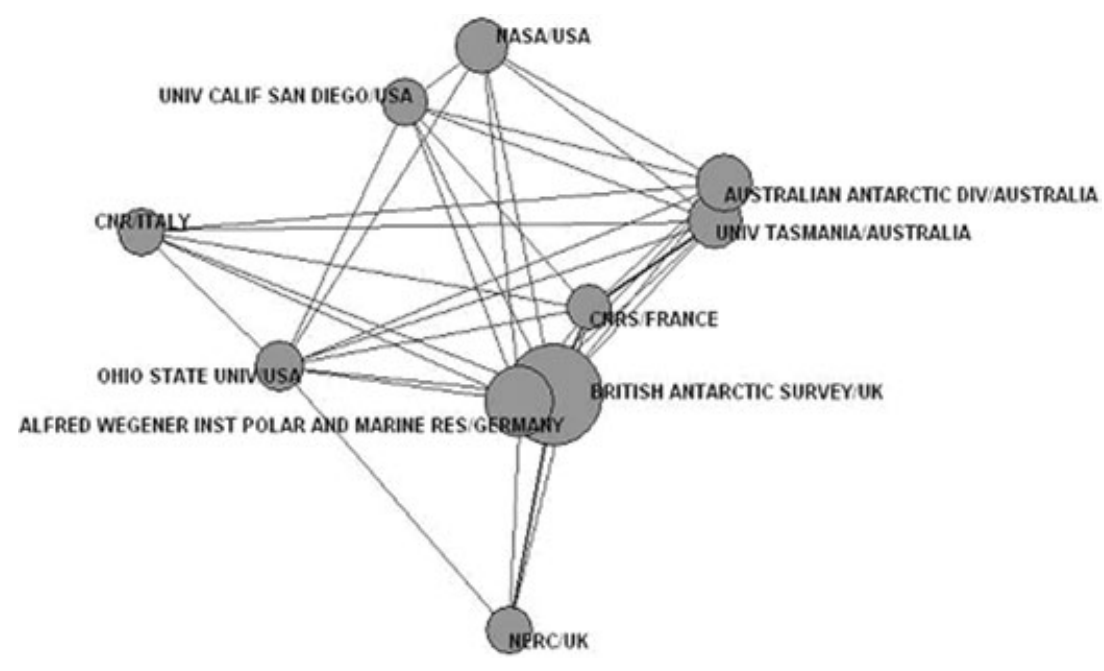

Fig. 3 Collaboration network among the ten most productive organizations in terms of the output of multinational journal publications with "antarc*" in the title, based on the annual CDROMs of the Science Citation Index, 1980-2004 $(N=2726)$. Line thickness and proximity of the circles indicates collaboration intensity between the institutions.
The USA alone contributed more than one quarter of all publications during the period, and, of the most productive individual organizations, one of three institutions in the list was American. The USA deploys the greatest manpower to the continent and maintains the largest research complex there. The USA has one of the highest per capita gross domestic expenditures on research and development, which is almost double that of the UK (Table 2). As was also seen in the case of journal publications in ocean science and engineering (Dastidar 2004), the most productive countries have higher per capita gross domestic expenditures on research and development.

International collaboration is an important element in the Antarctic Treaty, which was originally signed in 1959 (http://www.ats.aq/uploaded/treaty_original.pdf). To promote international cooperation, Article 3 of the treaty calls for the exchange of personnel and scientific results between the parties to the treaty. The 16th Antarctic Treaty Consultative Meeting declared 1991-2000 the Decade of International Antarctic Scientific Cooperation (Cohen 2002). This study has shown a marked increase in one indicator of international scientific cooperation in Antarctica: publications authored by writers from different countries.

An important subject beyond the scope of this brief paper is the research topics of the journal publications relating to Antarctica during the period in question. It would be extremely interesting to identify Antarctic research trends in this way, and it is hoped that this will be the subject of further analysis.

\section{Acknowledgements}

The author expresses his gratitude to Prof. Olle Persson, Dept of Sociology, Umeå University, Sweden, for his guidance and constructive suggestions. The author is thankful to Dr José Retamales, director of the Chilean Antarctic Institute and chairman of the Council of Managers of National Antarctic Programs, for his suggestions and for showing keen interest in the work. The author is also thankful to Dr B.S. Aggarwal for editing an earlier version of the manuscript.

\section{References}

Cohen H.K. (ed.) 2002. Handbook of the Antarctic Treaty System. 9th edn. Washington DC: US Department of State.

Dastidar P.G. 2004. Ocean science \& technology research across the countries: a global scenario. Scientometrics 59, 1527.

Dastidar P.G. \& Persson O. 2005. Mapping the global structure of Antarctic research vis-à-vis Antarctic Treaty System. Current Science 89, 11552-11554.

Dastidar P.G. \& Ramachandran S. 2005. Engineering research in ocean sector: an international profile. Scientometrics 65 , 199-213.

O'Connor M. \& Woodford F. P. 1978. Writing scientific papers in English. London: Pitman Medical.

Persson O. 2004. Bibexcel. Downloaded from the internet at http://www.umu.se/inforsk/Bibexcel on 27 February 2007.

Yank V. \& Rennie D. 1999. Disclosure of researcher contributions: a study of original research articles in The Lancet. Annals of Internal Medicine 130, 661-670. 